\title{
A metagenomic study of methanotrophic microorganisms in Coal Oil Point seep sediments
}

Othilde Elise Håvelsrud 1,2,3, Thomas HA Haverkamp ${ }^{3,4}$, Tom Kristensen ${ }^{2,3}$, Kjetill S Jakobsen ${ }^{3,4}$ and Anne Gunn Rike ${ }^{1 *}$

\begin{abstract}
Background: Methane oxidizing prokaryotes in marine sediments are believed to function as a methane filter reducing the oceanic contribution to the global methane emission. In the anoxic parts of the sediments, oxidation of methane is accomplished by anaerobic methanotrophic archaea (ANME) living in syntrophy with sulphate reducing bacteria. This anaerobic oxidation of methane is assumed to be a coupling of reversed methanogenesis and dissimilatory sulphate reduction. Where oxygen is available aerobic methanotrophs take part in methane oxidation. In this study, we used metagenomics to characterize the taxonomic and metabolic potential for methane oxidation at the Tonya seep in the Coal Oil Point area, California. Two metagenomes from different sediment depth horizons (0-4 cm and 10-15 cm below sea floor) were sequenced by 454 technology. The metagenomes were analysed to characterize the distribution of aerobic and anaerobic methanotrophic taxa at the two sediment depths. To gain insight into the metabolic potential the metagenomes were searched for marker genes associated with methane oxidation.

Results: Blast searches followed by taxonomic binning in MEGAN revealed aerobic methanotrophs of the genus Methylococcus to be overrepresented in the 0-4 cm metagenome compared to the 10-15 cm metagenome. In the 10-15 cm metagenome, ANME of the ANME-1 clade, were identified as the most abundant methanotrophic taxon with $8.6 \%$ of the reads. Searches for particulate methane monooxygenase (pmoA) and methyl-coenzyme M reductase $(\mathrm{mcr} A)$, marker genes for aerobic and anaerobic oxidation of methane respectively, identified pmoA in the 0-4 cm metagenome as Methylococcaceae related. The $m c r A$ reads from the 10-15 cm horizon were all classified as originating from the ANME-1 clade.

Conclusions: Most of the taxa detected were present in both metagenomes and differences in community structure and corresponding metabolic potential between the two samples were mainly due to abundance differences.

The results suggests that the Tonya Seep sediment is a robust methane filter, where taxa presently dominating this process could be replaced by less abundant methanotrophic taxa in case of changed environmental conditions.
\end{abstract}

\section{Background}

The Coal Oil Point seep area (COP), located in the Santa Barbara Channel, California, is one of the most active seep areas in the world [1]. Seepage of the greenhouse gas methane and other hydrocarbons has occurred in this area for over 500000 years [2]. The methane emitted from the COP is mainly of

\footnotetext{
* Correspondence: agr@ngi.no

'Norwegian Geotechnical Institute, Sognsveien 72, P.O. Box 3930 Ullevål

Stadion, N-0806 Oslo, Norway

Full list of author information is available at the end of the article
}

thermogenic origin and the daily emission has been estimated to be at least 40 metric tons $[1,3]$.

At a global scale, the oceans only make up about $2 \%$ of the global methane emission budget [4]. This low level is explained by prokaryotic oxidation of methane in marine sediments and bedrocks before it reaches the water column [5].

The oxygen penetration level in marine sediments is shallow, so most of the methane oxidation takes place at anaerobic conditions. Anaerobic oxidation of methane (AOM) is assumed to be a coupling of reversed methanogenesis and sulphate reduction. This process is likely

\section{() Biomed Central}


performed by the yet uncultured anaerobic methanotrophic archaea (ANME) in syntrophy with sulphate reducing bacteria (SRB). Based on phylogeny, ANME can be divided into three clades: ANME-1, ANME-2 and ANME-3 [6-9]. ANME-2 and ANME-3 are affiliated to the Methanosarcinales, while ANME-1 is only distantly related to the Methanosarcinales and Methanomicrobiales [7-9]. Both ANME-1 and ANME-2 are associated with sulphur reducing deltaproteobacteria of the Desulfosarcina/Desulfococcus-branch $[7,9,10]$. ANME-3 is mainly associated with SRB strains closely related to Desulfobulbus [6].

The reversed methanogenesis model for AOM has gained support by a metagenomic study on ANME at Eel River [11] and sequencing of an ANME-1 draft genome [12]. In these studies sequence homologues of all enzymes needed for $\mathrm{CO}_{2}$-based methanogenesis with exception of $\mathrm{N}^{5}, \mathrm{~N}^{10}$-methylene-tetrahydromethanopterin reductase (mer) were identified. Methyl-coenzyme $M$ reductase $(m c r A)$ is assumed to catalyze the first step of AOM and the last step of methanogenesis, and is therefore a marker gene for both processes. Similarly, dissimilatory sulphite reductase $(d s r \mathrm{AB})$ is often used as a marker gene for SRB [13].

When oxygen is present, aerobic methanotrophs are active in methane oxidation. Known aerobic methanotrophs include representatives of Gammaproteobacteria, Alphaproteobacteria and Verrucomicrobia [14-18]. These organisms convert methane to methanol using the enzyme methane monooxygenase [17]. The particulate, membrane bound version of methane monooxygenase ( $p m o \mathrm{~A})$, found in all aerobic methanotrophs (with exception of Methanocella), is used as a marker gene for aerobic oxidation of methane [19]. The methanol formed is converted to formaldehyde, which is assimilated by one of two known pathways. Type I and type II methanotrophs utilize the ribulose monophosphate pathway and the serine pathway respectively. Type $x$ methanotrophs use primarily the ribulose monophosphate pathway, but possess the enzymes needed for the serine pathway as well [20].

Stable isotope probing and sequencing of $16 \mathrm{~S}$ rDNA and pmoA, as well as lipid biomarker analysis, have detected type-I aerobic methanotrophs in sediments and biofilms at the COP Shane and Brian seeps [21,22]. Recently, measurements of average $\delta^{13} \mathrm{C}$ of carbonates and lipid biomarkers associated with ANME and SRB also indicated occurrence of AOM at the Brian seep [23]. Another survey at the Brian seep detected ANME2 at $6-9 \mathrm{~cm}$ bsf (below sea floor) by FISH (Fluorescent in situ hybridization) [24].

In the present study, we have used metagenomics to characterize the taxonomic and metabolic potential for both aerobic and anaerobic methane oxidation in two sediment samples from different depths at the Tonya seep (COP). By avoiding PCR amplification and primer target specificity, the metagenomics approach offered further insight into the taxonomy and metabolic potential of the prokaryotic communities of the methane seep sediments.

\section{Results}

\section{Gas measurements and methane oxidation rate}

The average methane oxidation rate based on 11 measurements in the top $15 \mathrm{~cm}$ of the seep sediments was $156 \pm 64 \mathrm{nmol} \mathrm{cm}^{-3} \mathrm{day}^{-1}$. Still, the gas emitted from the Tonya seep sediments into the water phase contained a large fraction of methane. Even after travelling $25 \mathrm{~m}$ through the water column, where dissolved $\mathrm{O}_{2}$ and $\mathrm{N}_{2}$ entered the bubbles, the two gas samples contained $80.4 \%$ (gas sample I) and $68.1 \%$ (gas sample II) methane. When $\mathrm{O}_{2}$ and $\mathrm{N}_{2}$ were excluded, and the hydrocarbon and $\mathrm{CO}_{2}$ content were normalized, methane accounted for $93.6 \%$ in both gas samples. The remainder consisted of $\mathrm{CO}_{2}$ and short chain hydrocarbons (C2, C3, i-C4 and n-C4).

\section{Metagenome creation through filtering of reads}

454 sequencing resulted in 395540 reads for the $0-4 \mathrm{~cm}$ sample and 282964 reads for the $10-15 \mathrm{~cm}$ sample. Replicate filtering of the metagenomes removed $33.03 \%$ of the reads from the $0-4 \mathrm{~cm}$ sample and $31.31 \%$ of the reads in the $10-15 \mathrm{~cm}$ sample. The resulting metagenomes consisted of 264902 reads (average length $413 \pm$ 138 bases, range 29-1907 bases) for the 0-4 cm sample and 194360 reads (average length of $419 \pm 134$ bases, range $29-1458$ bases) for the $10-15 \mathrm{~cm}$ sample. All further analyses were performed on these metagenomes (Figure 1). Unless other ways specified, all percentages throughout the text are given as percent of total reads for each filtered metagenome.

Estimated effective genome sizes (EGS) were 4.8 Mbp and 4.0 Mbp for the $0-4 \mathrm{~cm}$ and $10-15 \mathrm{~cm}$ sample respectively (Additional file 1 , Table $\mathrm{S} 1$ ).

\section{Rarefaction analysis}

Rarefaction analysis at the most resolved level of the NCBI taxonomy in MEGAN showed the taxonomic richness detected in the sediment samples (Figure 2). Including all assigned taxa, 1034 and 882 leaves were detected in the 0-4 cm and 10-15 cm metagenome respectively. Of these, $785(0-4 \mathrm{~cm})$ and $596(10-15 \mathrm{~cm})$ were bacterial and $58(0-4 \mathrm{~cm})$ and $127(10-15 \mathrm{~cm})$ archaeal. The rarefaction curves for bacterial and total taxa indicated that not all the taxonomic richness in the sediment was accounted for in our metagenomes. Still, the curves were levelling off from a straight line already at $10 \%$ of the metagenome size indicating repeated 


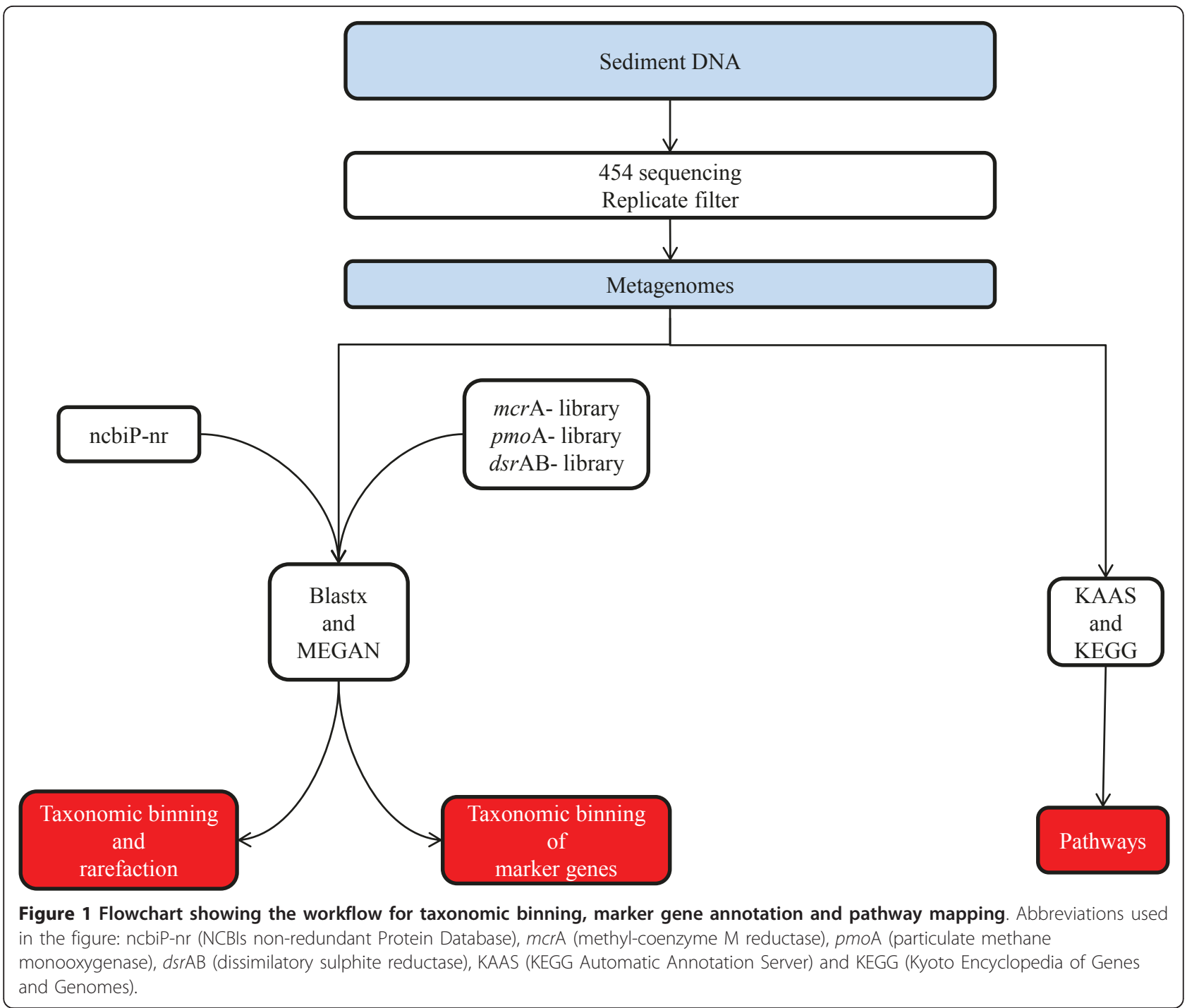

sampling of the same taxon. It is therefore likely that abundant taxa in the sediments were accounted for in the two metagenomes.

While most of the archaeal taxa in the $10-15 \mathrm{~cm}$ metagenome were accounted for, the number of taxa in the $0-4 \mathrm{~cm}$ was still increasing at $100 \%$ sampling. This difference is likely due to the low abundance of Archaea in the $0-4 \mathrm{~cm}$ metagenome $(0.97 \%$ of reads) compared to the $10-15 \mathrm{~cm}$ metagenome (18.09\% of reads) as shown in Figure 3.

\section{Taxonomic binning}

There was a significant difference in the proportion of reads assigned to Bacteria and Archaea for the two metagenomes (Figure 3). In the $0-4 \mathrm{~cm}$ metagenome $60.87 \%$ of the reads were assigned to Bacteria and $0.97 \%$ to Archaea, while in the $10-15 \mathrm{~cm}$ metagenome $47.14 \%$ of the reads were assigned to Bacteria and as much as
18.09\% to Archaea. This shift in the prokaryotic community structure suggests that Archaea thrive better and thereby also are likely to contribute more to the metabolism in the 10-15 cm sediment horizon.

Xipe analyses of the binned reads (confidence cut-off of $0.95,0.98$ and 0.99 ) at the phylum level (Table 1) and at the genus level (Additional file 2, Tables S2 and Additional file 3, Table S3) showed a significant difference between the two metagenomes as to the most abundant taxa [25]. The high abundance of Archaea in the $10-15 \mathrm{~cm}$ metagenome compared to the $0-4 \mathrm{~cm}$ metagenome was striking at the phylum level as well (Table 1). In the 10-15 cm metagenome, reads assigned to Proteobacteria and to "Archaeal environmental samples" were almost equally abundant, representing $15.45 \%$ and $13.03 \%$ of the reads respectively. In contrast, "Archaeal environmental samples" represented only $0.15 \%$ of the $0-4 \mathrm{~cm}$ metagenome, where reads assigned 


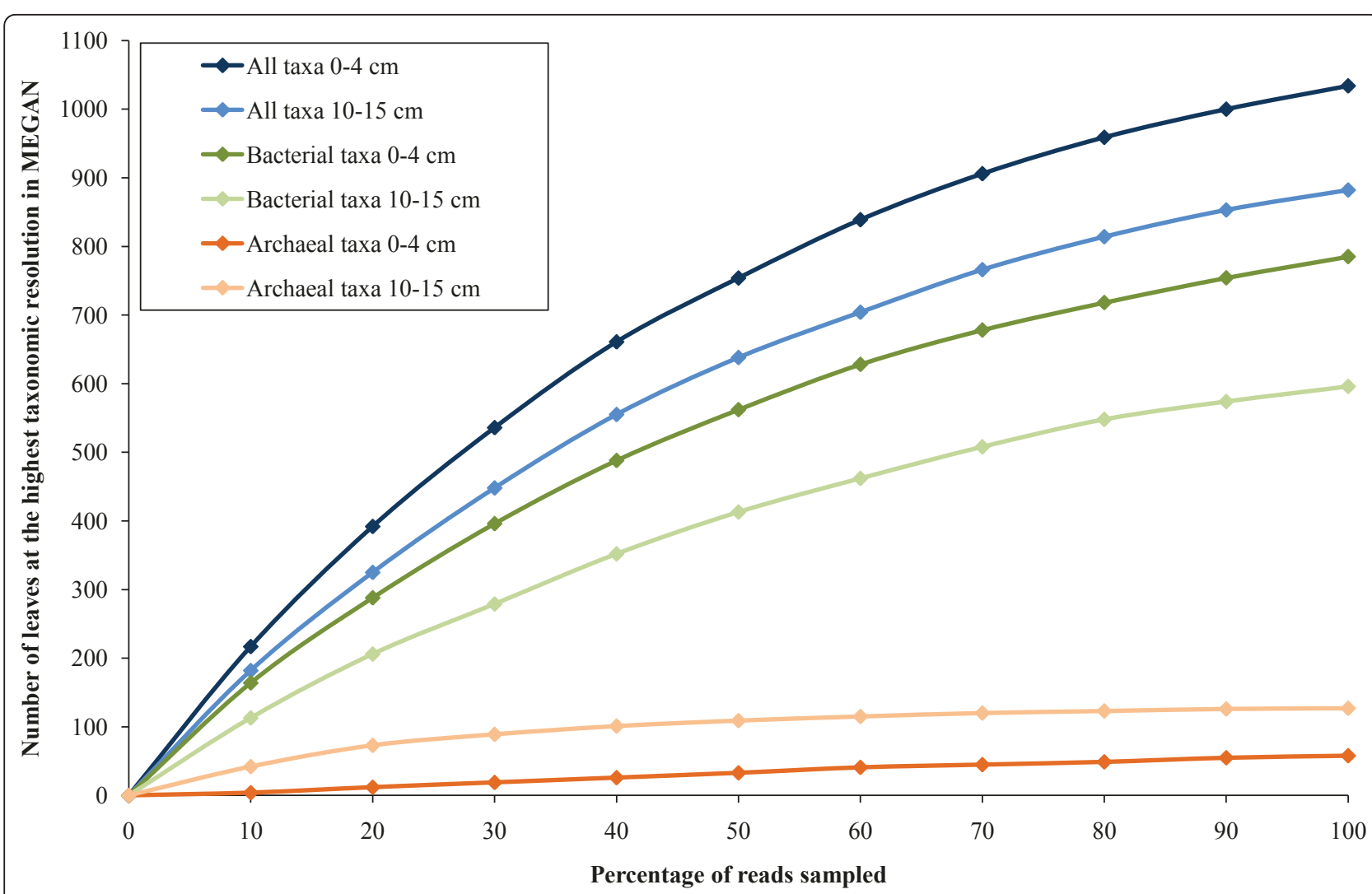

Figure 2 Rarefaction curves created in MEGAN. Rarefaction analysis was performed at the most resolved taxonomic level of the NCBI taxonomy in MEGAN for each metagenome. The curves for all taxa include Bacteria, Archaea, Eukaryota, Viruses, unclassified and other sequences.

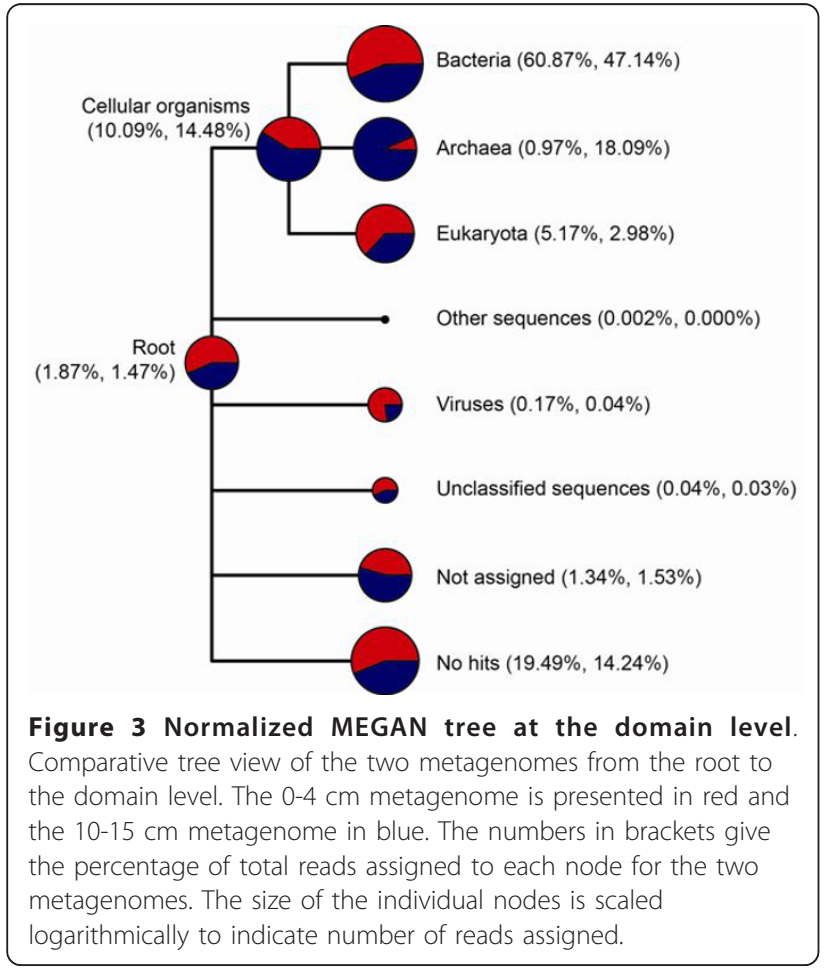

to Proteobacteria representing $31.07 \%$ were clearly most abundant (Table 1). Euryarchaeota was also significantly better represented in the 10-15 $\mathrm{cm}$ metagenome.

Among the Proteobacteria, Sulfurovum was the most abundant genus in the $0-4 \mathrm{~cm}$ metagenome (Additional file 2, Table S2). This sulphur oxidizing genus, with its versatile energy metabolism, is known to thrive in sediments related to hydrothermal seepage where reductive and oxidative states in the mixing zone often fluctuate [26]. Sulfurovum was almost four times more abundant in the $0-4 \mathrm{~cm}$ metagenome compared to the $10-15 \mathrm{~cm}$ metagenome. This is consistent with oxidative zones being its preferred habitat [26].

\section{Taxa potentially involved in methane oxidation}

The methane oxidation measurements in the sediment cores indicated methanotrophic activity at both sediment depths. The metagenomes were searched for reads assigned to known methanotrophic genera that might be involved in methane oxidation. Methylococcus was the predominant aerobic methanotrophic genus in both metagenomes, but was significantly more abundant in the $0-4 \mathrm{~cm}$ metagenome where it accounted for $0.16 \%$ 
Table 1 Reads assigned to bacterial and archaeal taxa at the phylum-level in MEGAN

\begin{tabular}{|c|c|c|c|c|c|c|}
\hline \multirow[t]{2}{*}{ Domain } & \multirow[t]{2}{*}{ Phyla } & \multicolumn{2}{|c|}{$0-4 \mathrm{~cm}$ metagenome } & \multicolumn{2}{|c|}{$10-15 \mathrm{~cm}$ metagenome } & \multirow{2}{*}{$\begin{array}{l}\text { Significant } \\
\text { difference }^{1}\end{array}$} \\
\hline & & Reads assigned & Percent of reads & Reads assigned & Percent of reads & \\
\hline Bacteria & Proteobacteria & 82318 & 31.07 & 30020 & 15.45 & *** \\
\hline Bacteria & - Gammaproteobacteria ${ }^{2}$ & 27876 & 10.52 & 6442 & 3.31 & $* * *$ \\
\hline Bacteria & - Deltaproteobacteria ${ }^{2}$ & 13777 & 5.20 & 12015 & 6.18 & $* * *$ \\
\hline Bacteria & - Alphaproteobacteria ${ }^{2}$ & 8355 & 3.15 & 2416 & 1.24 & $* * *$ \\
\hline Bacteria & - Epsilonproteobacteria ${ }^{2}$ & 5198 & 1.96 & 877 & 0.45 & $* * *$ \\
\hline Bacteria & - Betaproteobacteria ${ }^{2}$ & 3045 & 1.15 & 1067 & 0.55 & $* * *$ \\
\hline Bacteria & - Zetaproteobacteria ${ }^{2}$ & 282 & 0.11 & 77 & 0.04 & $* * *$ \\
\hline Bacteria & Bacteroidetes & 16782 & 6.34 & 6073 & 3.12 & $* * *$ \\
\hline Bacteria & Planctomycetes & 3657 & 1.38 & 2447 & 1.26 & \\
\hline Bacteria & Firmicutes & 3620 & 1.37 & 4445 & 2.29 & $* * *$ \\
\hline Archaea & Euryarchaeota & 1353 & 0.51 & 6772 & 3.48 & $* * *$ \\
\hline Archaea & Archaeal environmental samples & 404 & 0.15 & 25317 & 13.03 & $* * *$ \\
\hline
\end{tabular}

The table presents number of reads assigned at the phylum level in MEGAN. For the phylum Proteobacteria, subsets of reads assigned proteobacterial classes are shown. All percentages are given as the percentage of total reads for each filtered metagenome. (Only phyla with at least $1 \%$ of the total unique reads in one or both samples are included.)

$1 * * *$ indicates $99 \%$ confidence interval

${ }^{2}$ Reads assigned to Proteobacteria at the class level in MEGAN

of the reads compared to the $10-14 \mathrm{~cm}$ metagenome where it accounted for $0.04 \%$ of the reads (Figure 4 and Additional file 2, Table S2). Although reads assigned to the aerobe methanotrophs Methylomonas, Methylocella and Methylacidiphilum were also detected, Methylococcus was approximately 10 and 2.5 times more abundant than these genera combined in the $0-4 \mathrm{~cm}$ and $10-15$ $\mathrm{cm}$ metagenome respectively.
ANME groups were the predominant anaerobic methanotrophs in the sediments. Since taxonomic classification of reads in MEGAN was based on the NCBI taxonomy, the ANME clades were not recognized as independent taxa. The artificial taxon "Archaeal environmental samples" was however represented (Additional file 3, Table S3). Inspection of the reads assigned to this taxon revealed their assignment to ANME-1 and

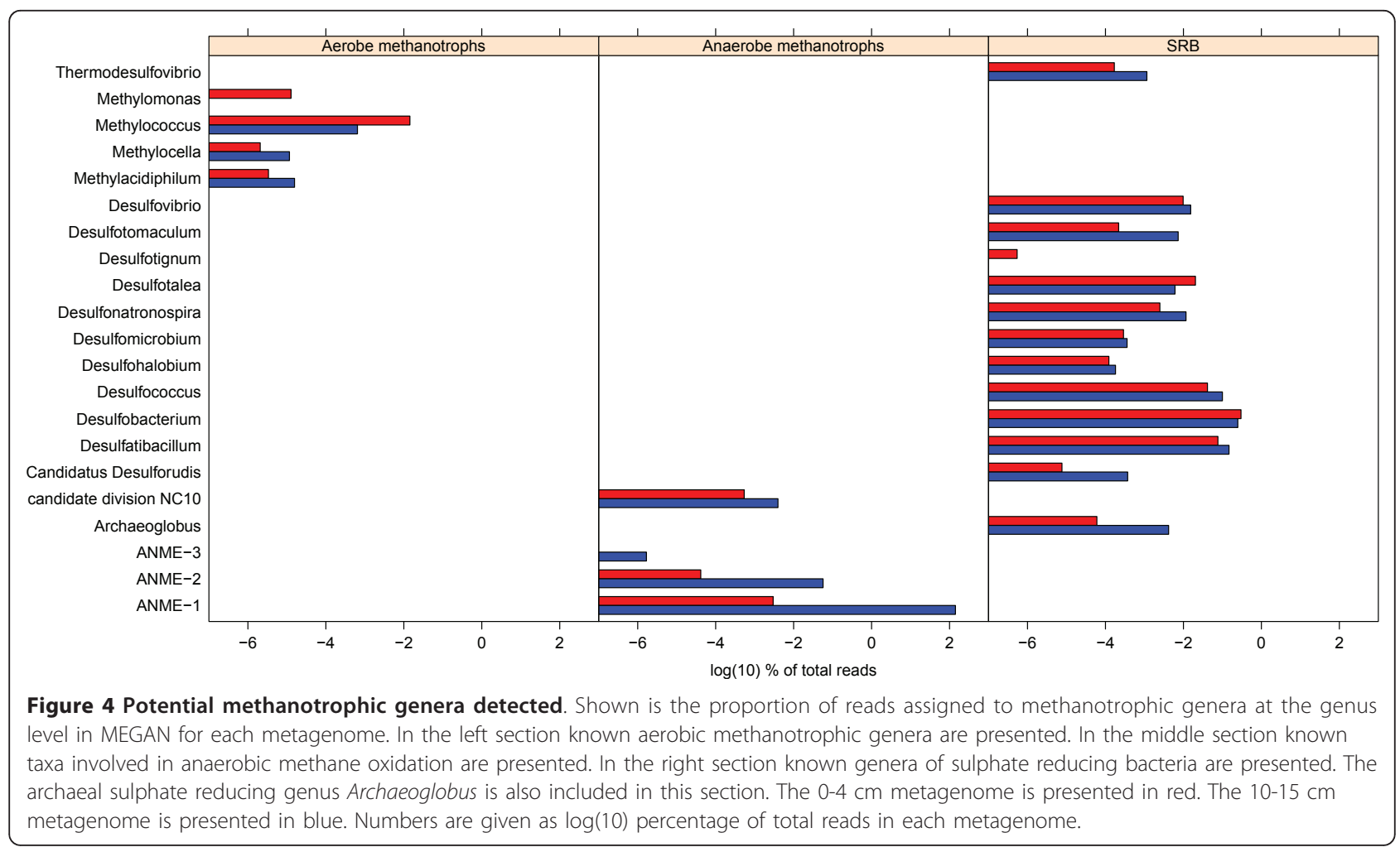


ANME-2 fosmids isolated from Eel River [11] or to "uncultured archaeon". Further inspection of the best hits for the reads assigned to "uncultured archaeon" (mean bit score 146.8) showed that most of these reads were associated to ANME as well, while a few reads were assigned to fosmids isolated from methane seeps offshore Japan [12,27-29] (Table 2).

The ANME-1 clade was by far the anaerobic methanotroph with most assigned reads, although ANME-2 and ANME-3 also were present in the 10-15 cm metagenome (Figure 4). ANME-1 and ANME-2 were detected with low abundance in the $0-4 \mathrm{~cm}$ metagenome. The high abundance of ANME in the 10-15 cm metagenome indicates that AOM caused the high methane oxidation rates measured at this depth.

ANME are assumed to live in syntrophy with SRB. The most abundant genera of SRB in the metagenomes from the Tonya seep were Desulfococcus, Desulfobacterium and Desulfatibacillum (Figure 4). These genera were abundant in both metagenomes, and Desulfococcus, a common partner of ANME $[7,9,10]$, especially so in the 10-15 cm metagenome (Additional file 2, Table S2).

Reads assigned to the bacterial NC10 group were present in both metagenomes (Figure 4). It has been proposed that Candidatus Methylomirabilis oxyfera of the NC10 group can oxidize methane anaerobically without an archaeal partner [30,31]. A pathway of "intra-aerobic" methane oxidation where an intracellular supply of oxygen is produced by metabolism of nitrite to oxygen and dinitrogen has been suggested. This intracellularly produced oxygen is then used for the oxidation of methane via pmoA [32]. Reads assigned to NC10 were significantly overrepresented (99\% confidence interval) in the 10-15 cm metagenome compared to the $0-4 \mathrm{~cm}$ metagenome. Still, there was far less reads (approximately 1:100) assigned to NC10 than to ANME- 1 in the 10-15 $\mathrm{cm}$ metagenome.

\section{Methane oxidation pathways}

To gain insight into the metabolic pathways for methane oxidation at the Tonya Seep, we annotated the reads from each metagenome to $\mathrm{KO}$ and $\mathrm{EC}$ numbers and plotted them onto KEGG pathway maps. In this way, the methane monooxygenase gene (EC: 1.14 .13 .25$)$ was identified in the $0-4 \mathrm{~cm}$ sample, supporting the idea of aerobic methane oxidation in this sediment horizon. This gene was not detected in the $10-15 \mathrm{~cm}$ metagenome.

All the genes needed for AOM/methanogenesis, including $m c r A$ (EC: 2.8 .4 .1 ), were detected in the 10-15 $\mathrm{cm}$ metagenome (Figure 5). In the $0-4 \mathrm{~cm}$ metagenome, the genes for methylenetetrahydromethanopterin dehydrogenase ( $m t d$, EC: 1.5 .99 .9$)$ and methenyltetrahydromethanopterin cyclohydrolase ( $m c h, \mathrm{EC}: 3.5 .4 .27$ ) were not detected. This is likely due to the low abundance of reads assigned to Euryarchaeota and "Archaeal environmental samples", and thereby low coverage of genes encoded by these taxa, in the $0-4 \mathrm{~cm}$ metagenome. In total, 1757 reads were assigned to these taxa in the $0-4$ $\mathrm{cm}$ metagenome. With an average sequence length of 413 bases this gives a total of $0.7 \mathrm{M}$ bases, while the average ANME-1 genome size is estimated to be 3.3-3.6 Mbp (Table 1) [12].

Anaerobic oxidation of methane is usually associated with dissimilatory sulphate reduction, where adenylylsulphate reductase (EC: 1.8.99.2) first reduces sulphate to sulphite before dissimilatory sulphite reductase (EC: 1.8.99.3) reduces sulphite to sulphide [13]. These genes were detected in both metagenomes.

\section{Marker genes}

To obtain a more precise picture of taxa actually capable of methane oxidation in our sediment, the metagenomes were compared with libraries of marker genes for methane oxidation. Estimated probabilities for

Table 2 "Archaeal environmental samples"- reads assigned to ANME-sequences

\begin{tabular}{lcccc}
\hline Clade & \multicolumn{2}{c}{$\mathbf{0 - 4} \mathbf{~ c m}$ metagenome } & \multicolumn{2}{c}{$\mathbf{1 0 - 1 5}$ cm metagenome } \\
& Reads assigned & Percent of reads & Reads assigned & Percent of reads \\
\hline ANME-1, Eel River [11,27] & 27 & 0.01 & 3532 & 1.82 \\
ANME-1, Black Sea [12] & 177 & 0.07 & 12752 & 6.56 \\
ANME-1b, Black Sea [28] & 8 & 0.00 & 429 & 0.22 \\
Total ANME-1 & $\mathbf{2 1 2}$ & $\mathbf{0 . 0 8}$ & $\mathbf{1 6 7 1 3}$ & $\mathbf{8 . 6 0}$ \\
ANME-2, Eel River [11] & 20 & 0.01 & 534 & 0.27 \\
ANME-2a [28] & 11 & 0.00 & 14 & 0.01 \\
ANME-2c [28] & 2 & 0.00 & 12 & 0.01 \\
Total ANME-2 & $\mathbf{3 3}$ & $\mathbf{0 . 0 1}$ & $\mathbf{0 . 2 9}$ \\
ANME-3, Hydrate Ridge [28] & 0 & 0.00 & 6 & 0.00 \\
Total ANME-3 & $\mathbf{0}$ & $\mathbf{0 . 0 0}$ & $\mathbf{6}$ & $\mathbf{0 . 0 0}$ \\
\hline Total ANME & $\mathbf{2 4 5}$ & $\mathbf{0 . 0 9}$ & $\mathbf{1 7 2 7 9}$ \\
\hline
\end{tabular}

The table presents reads assigned to Archaeal environmental samples" further classified as ANME. All percentages are given as the percentage of total reads for each filtered metagenome. 


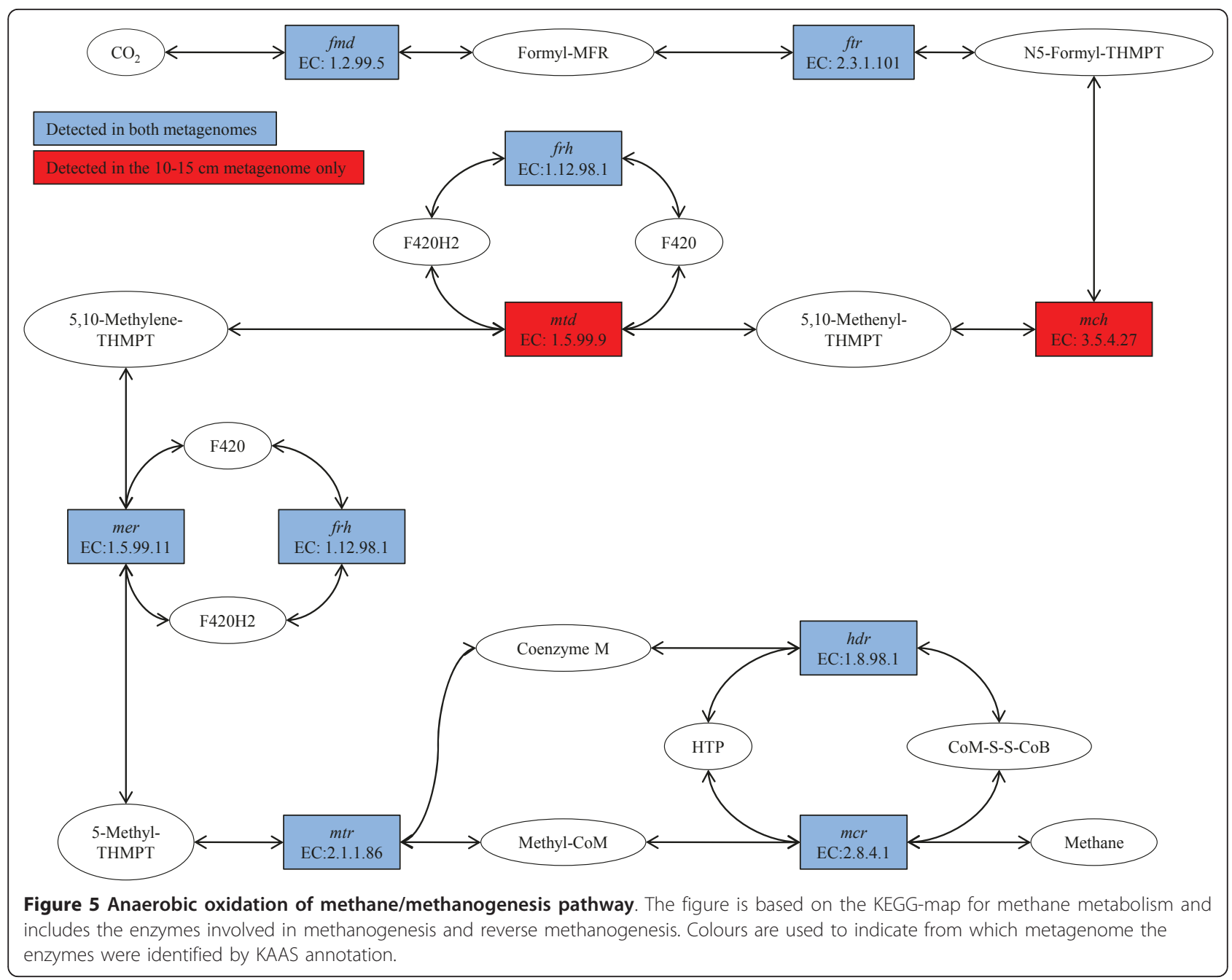

identifying the specific marker genes were used to calculate expected hits to marker genes in a scenario where all organisms in the communities contained the gene in question (Additional file 1, Table S1). Based on these expected numbers, and the number of marker genes actually detected, we estimated the fraction of the community containing the gene. Eight reads in total matched pmoA, the marker gene for aerobic methane oxidation (Figure 6). In MEGAN, one of these was assigned to the genus Methylococcus of the family Methylococcaceae while six reads were assigned to unclassified Methylococcaceae. This point towards Methylococcaceae as the most important family of aerobic methane oxidizers at the Tonya seep sediments, as was also indicated by taxonomic abundance. Seven out of eight reads assigned to pmoA were from the $0-4 \mathrm{~cm}$ sample, supporting that aerobic methane oxidation is conducted in the shallower layer of the sediment. The estimated fraction of the community coding for pmoA, based on marker gene detection, was calculated to
$12.9 \%$ and $1.5 \%$ in the $0-4 \mathrm{~cm}$ and $10-15 \mathrm{~cm}$ respectively (Additional file 1, Table S1).

The marker gene for AOM, mcrA, is also a key gene in methanogenesis, where it catalyzes the last step. The 0-4 $\mathrm{cm}$ sample contained only one $\mathrm{mcr}$ A read, assigned to the methanogenic genus Methanosarcina (Figure 6). In the $10-15 \mathrm{~cm}$ sample 28 reads matching mcrA were found, all assigned to ANME-1. Based on EGS and expected number of reads matching $m c r A$, the estimated fraction of the community in the 10-15 $\mathrm{cm}$ sample made up of ANME-1 was 77.4\% (Additional file 1, Table S1).

In order to detect possible SRB partners of ANME, we compared the two metagenomes to a $d s r \mathrm{AB}$ library. Of 60 hits, 33 were assigned to the reversed form of $d s r \mathrm{AB}$ found in sulphur compound-oxidizing bacteria. Sixteen and eleven $d s r \mathrm{AB}$ reads from the possible SRB partners of ANME were detected in the 0-4 cm and 10-15 cm metagenomes respectively, estimations based on the probability of detecting this gene thereby indicate that $43.2 \%$ and $24.6 \%$ of the $0-4 \mathrm{~cm}$ and $10-15 \mathrm{~cm}$ 


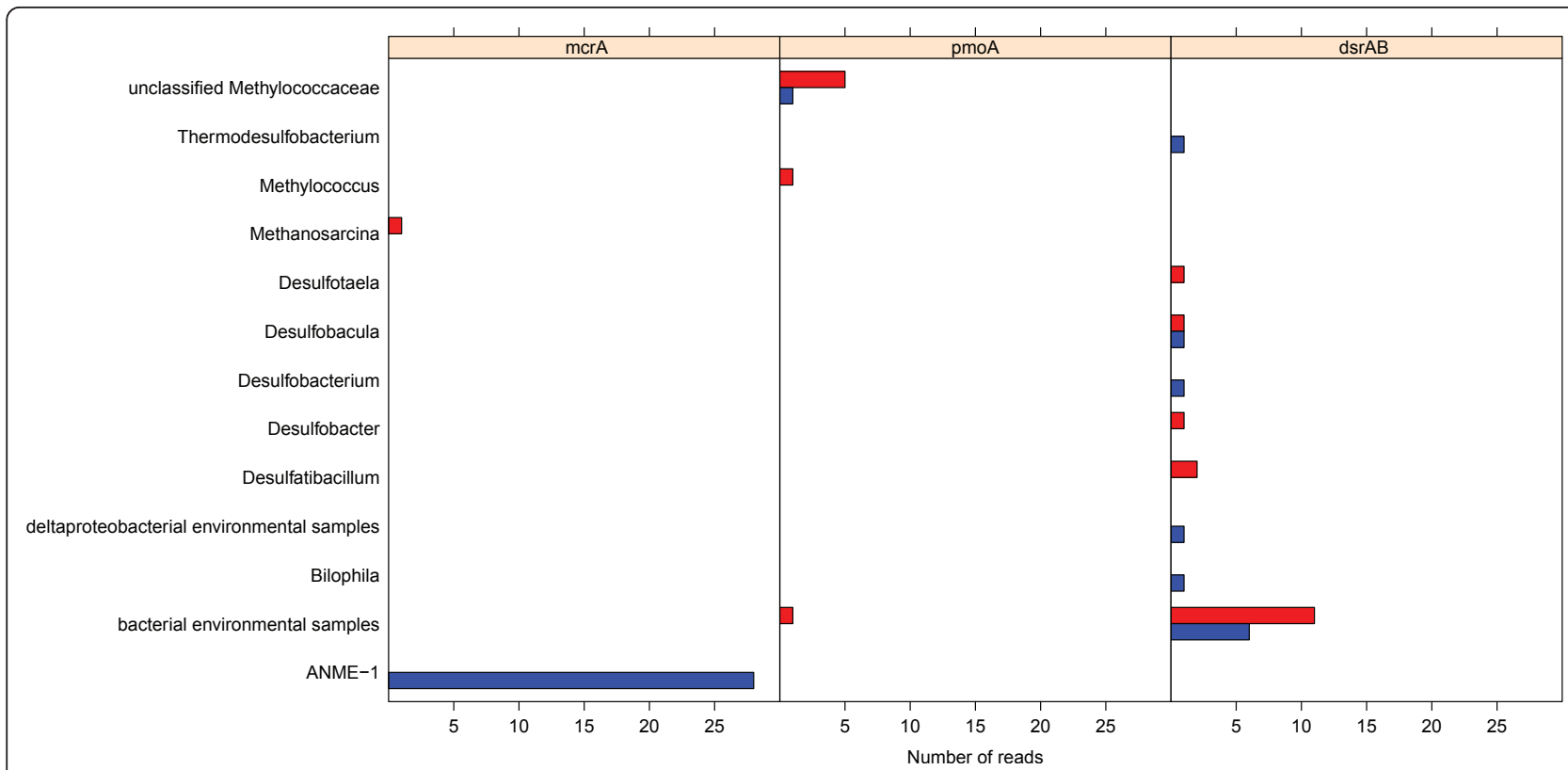

Figure 6 Taxonomic distribution of marker genes for methane oxidation. Shown is the number of reads matching marker genes associated with oxidation of methane and the taxonomic distribution of these reads in each metagenome. Reads matching the marker genes for anaerobic oxidation of methane $(\mathrm{mcr} A)$, aerobic oxidation of methane $(\mathrm{pmoA})$ and sulphate reduction $(\mathrm{ds} r \mathrm{AB})$ are presented in the left, middle and right section respectively. The $0-4 \mathrm{~cm}$ metagenome is presented in red and the $10-15 \mathrm{~cm}$ metagenome in blue.

community were made up by SRB respectively (Additional file 1, Table S1).

Most SRB dsrAB reads were assigned to "bacterial environmental samples" and the deltaproteobacterial genera Desulfotaela, Desulfobacula, Desulfobacterium, Desulfobacter, Desulfatibacillum and Bilophila (Figure 6). The reads assigned to "bacterial environmental samples" matched clones from a diverse range of sediments [33-41] and one clone from an acidic fan soil sample [42]. Eight of the reads assigned to "bacterial environmental samples" (six from the $0-4 \mathrm{~cm}$ metagenome and two from the 10-15 cm metagenome) were most similar to dsr AB sequences from Deltaproteobacteria [33-39] (results not shown). None of the $d s r \mathrm{AB}$ reads were assigned to Desulfosarcina or Desulfococcus, the previously described syntrophic partners of ANME-1 $[7,9,10]$.

\section{Discussion}

\section{Methane oxidation rate}

Methane oxidation rates in our sediment cores were 156 $\pm 64 \mathrm{nmol} \mathrm{cm}^{-3} \mathrm{day}^{-1}$. This is much higher than the methane oxidation rates at the nearby Brian seep (6-87 $\mathrm{nmol} \mathrm{cm}{ }^{-3}$ day $^{-1}$ ) [24] and within the range of AOM at seeps with surface hydrates, mud volcanoes and gas chimneys ([13] and refs therein). It has been suggested that the relatively low methane oxidation rate at the Brian seep could be caused by the permeable, sandy sediments leading to low amounts of dissolved methane in the pore water [24]. Conversely, the higher methane oxidation rate at the Tonya seep could be due to the less permeable, relatively oily tar containing sediments at this seep.

\section{Taxonomic richness and coverage}

Taxonomic classification was based on a blastX query against the NCBI non-redundant Protein Database (ncbiP-nr). It has previously been shown that the prokaryotic representation in public sequence databases, such as the ncbiP-nr, is heavily biased towards taxa that are easily cultivable or of anthropogenic interest $[43,44]$. Many of the taxa represented are further only partially sequenced [44]. These issues may lead to false assignment of reads, especially if only the top hit is considered. By employing the LCA algorithm of MEGAN, most of these wrong assignments are avoided at the cost of more reads being assigned to taxa of low specificity or not being assigned at all $[45,46]$. Short reads may also be a source of ambiguous taxonomic classification, especially if they are from a highly conserved region of the genome or from a region susceptible to horizontal gene transfer $[44,45,47]$. We therefore calculated the average read length for reads assigned to different taxonomic levels in MEGAN to see if it decreased with decreasing taxonomic specificity (Additional file 4, Table S4). This was not the case as average lengths of reads assigned to all taxonomic levels in MEGAN (including "not assigned") were in the same range (approximately 
450 bases). Read with no hits against the ncbiP-nr were however considerably shorter (average read lengths of $263 \pm 181$ and $232 \pm 175$ bases in $0-4 \mathrm{~cm}$ and $10-15 \mathrm{~cm}$ metagenome respectively).

Rarefaction analyses indicated that the most abundant taxa of the Tonya Seep sediments were accounted for in our metagenomes. The taxonomic richness of prokaryotes, in combination with high EGS, does however lead to low coverage of most genomes represented in the metagenomes. Absence of a single marker gene assigned to a specific taxon might therefore be due to chance. Still, we detected more marker genes than expected based on the taxonomic binning of reads. This could be due to an overestimation of the EGS. It has previously been discussed that a bit score threshold of 60 (as used in this work according to the method developed by Raes et al. [48]) might discriminate against short reads, and that lowering of the threshold would result in decreased EGS [49]. A decreased EGS would in turn result in a reduction of the estimated fraction of the community carrying the marker genes $m c r \mathrm{~A}, p m o \mathrm{~A}$ and $d s r \mathrm{AB}$. Differences in copy number for organisms carrying the gene might also affect the expected number of hits.

\section{Aerobic methane oxidation}

Due to limited oxygen penetration, active aerobic methane oxidation is probably limited to a thin surface layer. The maximum oxygen penetration at the nearby Brian seep sediments was measured to a depth of 1.4 $\mathrm{cm}$ [24]. Due to high tar content, oxygen penetration in the sediments of the Tonya seep is expected to be more restricted than at the Brian seep.

Methane monooxygenase (EC: 1.14 .13 .25 ) was only detected in the $0-4 \mathrm{~cm}$ metagenome after plotting of KO and EC numbers onto KEGG pathway maps. Overrepresentation of aerobic methanotrophic genera and pmoA (based on library comparison) in the $0-4 \mathrm{~cm}$ metagenome compared to the $10-15 \mathrm{~cm}$ metagenome further support aerobic oxidation of methane in the 0-4 $\mathrm{cm}$ sediment sample (see Figures 4 and 6).

Both taxonomic binning of reads and marker gene classification point to type I methanotrophs of Methylococcaceae as the most important aerobic methane oxidizers in our samples. While Methylococcus was the aerobic methanotrophic genus with most reads assigned (see Figure 4), most of the detected pmoA reads were assigned to unclassified Methylococcaceae (see Figure 6). This indicates that uncultured type I methanotrophs might play an important role in aerobic methane oxidation at the Tonya Seep. Also in microbial mats and sediments of the nearby Shane and Brian seeps aerobic type I methanotrophs have been identified, while no type II methanotrophs were detected at either of these sites $[21,22]$. This is consistent with type I methanotrophs dominating over type II methanotrophs in most marine settings ([50]and refs therein).

\section{Anaerobic methane oxidation}

Genes for AOM were detected in both metagenomes (see Figure 5). The taxonomic binning of reads points to AMNE-1 as the predominant anaerobic oxidizer of methane in the Tonya seep sediment, especially in the $10-15 \mathrm{~cm}$ sediment sample. It is however, important to notice that ANME-1, due to the genome sequencing efforts [12], is the most sequenced ANME-clade, and therefore overrepresented in the database. This could skew our relative abundance results. However, the presence and dominance of ANME-1 was further supported by the $m c r A$ reads in our metagenomes (see Figure 6). This gene is identified in all ANME-clades, still all reads matching mcrA in the $10-15 \mathrm{~cm}$ metagenome were assigned to ANME-1. Taken together, these results provide strong evidence of ANME-1 being the most important clade for anaerobic methane oxidation in the Tonya seep sediments. In contrast, only ANME-2 was detected at the nearby Brian Seep [24]. ANME-1 and ANME-2 are known to co-occur in sediments, usually with one type more abundant than the other $[7,51,52]$. The environmental conditions that might regulate the relative abundance of the different ANME clades in marine sediments are still not known [7,51]. Differences in permeability of the sediments at the Tonya and Brian seeps could be one factor selecting for different ANME clades at the two sites.

\section{Sulphate reducing bacteria}

Anaerobic oxidation of methane is assumed to be coupled to dissimilatory reduction of sulphate. Both metagenomes had reads assigned to SRB genera, predominantly Desulfococcus, Desulfobacterium and Desulfatibacillum (see Figure 4). The ratio of total reads assigned to ANME related to reads assigned to each of these SRB genera in the 10-15 cm metagenome were ANME: Desulfobacterium; 16: 1, ANME Desulfatibacillum; 20:1 and ANME: Desulfococcus; 24: 1. The total ratio ANME: SRB (including "Bacteria environmental samples") was 4: 1 .

Reads assigned to dsr AB were detected in both metagenomes and classified to a diverse set of taxa (see Figure 6). Although the fraction of the community containing mcrA and $d s r \mathrm{AB}$, calculated based on sampling probability of the specific marker genes, is likely to be overestimated it gives a similar ratio of 3: 1 of mcrAcontaining organisms: dsrAB containing organisms as the taxonomic binning of reads. None of our $d s r \mathrm{AB}$ reads were assigned to the known ANME partner Desulfococcus, although this genus was one of the most abundant SRB genera in our metagenomes (see Figure 4). 
This does not imply absence of $d s r \mathrm{AB}$ among Desulfococcus in our samples; the gene was more likely missed by chance due to low coverage (see Additional file 2, Table S2).

ANME might also form syntrophic relationships to other bacteria than those most commonly recognized. ANME-2 has previously been detected to form physical associations to both Desulfobulbus and a member of the Betaproteobacteria, as well as their regular partners from the Desulfococcus/Desulfosarcina branch [53]. The main bulk of $d s r \mathrm{AB}$-reads in the 10-15 cm metagenome were assigned to "bacterial environmental samples" and the ANME partners might be found among these organisms. The "bacterial environmental samples" is however a diverse group and was also abundant in the $0-4 \mathrm{~cm}$ metagenome, where ANME were less abundant.

Our results do not indicate only one predominant ANME partner, but rather that several syntrophic partners may be involved. Diverse $d s r \mathrm{AB}$ signatures with only weak coupling to AOM have previously been detected in ANME-1 dominated sediments in the Gulf of Mexico [39]. This suggests that these seep environments have a high diversity of taxa involved in sulphate reduction.

\section{Conclusions}

By using 454 sequenced metagenomes we achieved an insight into the taxonomic richness of the seep sediments. Most of the taxa were present in both metagenomes and differences in community structure and corresponding metabolic potential between the two samples were due to abundance, indicating sliding boundaries between the different communities. Our approach provided strong evidence for the taxa responsible for methane oxidation. The Tonya Seep harboured several taxa potentially capable of methane oxidation under both aerobic and anaerobic conditions. This suggests that the sediment is a robust methane filter, where taxa presently dominating this important process could be replaced by less abundant taxa should the environmental conditions change.

\section{Methods}

\section{Sampling site}

Tonya Seep $\left(34^{\circ} 24.043^{\prime} \mathrm{N} ; 119^{\circ} 52.841^{\prime} \mathrm{W}\right)$ is located in the Coal Oil Point seep field offshore Santa Barbara, California, USA. Tonya Seep is primarily a single $2 \mathrm{~m}$ diameter pit with many vents inside that rapidly coalesce into a single plume. There was a high content of hydrocarbons and tar in the sediments. Four sediment cores, two for methane oxidation studies and two for metagenomic analysis, were collected at $25 \mathrm{~m}$ depth on July $16^{\text {th }} 2008$ by UC Santa Barbara Marine Operation divers. The polycarbonate liners used $(30 \mathrm{~cm}$ length and
$3.5 \mathrm{~cm}$ diameter) were treated with $70 \%$ ethanol and dried before sampling. The parallel cores (core I, II, III and IV) were sealed at the seafloor and kept on ice during transportation back to shore.

\section{Gas Sample Collection}

Two seep gas samples (Gas samples I and II) were collected in the surface waters above the seep. The samples were collected on two occasions from small vessels via an inverted funnel method in which seep gas bubbles were captured into $120 \mathrm{~mL}$ glass serum vials after rising through the water column. Bottles were capped underwater after filling to avoid contamination with atmospheric gases. Seep gases were analyzed by gas chromatography as previously described [54]. Error associated with the concentration measurements was $\pm 4 \%$.

\section{Methane oxidation rates}

Cores III and IV designated for methane oxidation rate (MOR) measurements were injected with radiotracer ${ }^{14} \mathrm{C}_{-} \mathrm{CH}_{4}\left(1 \mathrm{kBq}{ }^{14} \mathrm{CH}_{4}\right.$ dissolved in water, $20 \mu \mathrm{L}$ injection volume) at $2 \mathrm{~cm}$ intervals and incubated at near insitu temperature. After 18 hours the core was sub-sectioned and placed into vials with $1 \mathrm{M} \mathrm{NaOH}$ and quickly sealed, ending the incubation and trapping the $\mathrm{CO}_{2}$. A small sample of headspace $(0.2 \mathrm{~mL})$ was removed to determine $\mathrm{CH}_{4}$ concentration (which is not affected by the ${ }^{14} \mathrm{CH}_{4}$ spike) by GC-FID (Shimadzu GC4A, $6 \mathrm{ft}$ length 80/100 mesh Molsieve 13X packed column run isothermally at $140^{\circ} \mathrm{C}$ with $\mathrm{N}_{2}$ carrier flow at $15 \mathrm{~mL} \mathrm{~min}^{-1}$ ). The remaining ${ }^{14} \mathrm{CH}_{4}$ in the headspace of the vial was purged via a slow flow of air through a combustion tube filled with $\mathrm{Cu}(\mathrm{II})$-oxide and maintained at $850^{\circ} \mathrm{C}$. The resulting ${ }^{14} \mathrm{CO}_{2}$ was trapped using a mixture of phenethylamine and 2-methoxyethanol. The remaining ${ }^{14} \mathrm{CO}_{2}$, which was assumed to be microbially produced, was measured by first transferring the sediment into a $100 \mathrm{~mL}$ Erlenmeyer flask fitted with a small $(7 \mathrm{~mL})$ phenethylamine/ $\mathrm{NaOH}$-filled scintillation vial suspended beneath its rubber stopper. Six ml of hydrochloric acid $(6 \mathrm{M})$ was injected through the rubber stopper to degas the $\mathrm{CO}_{2}$ from the sediment $/ \mathrm{NaOH}$ slurry, and the flask was placed in a shaker for $\sim 8 \mathrm{hrs}$ to transfer the $\mathrm{CO}_{2}$ to the suspended scintillation vial. Radioactivity was quantified by scintillation counting (Beckman LSC 6500).

The ex-situ $\mathrm{CH}_{4}$ oxidation rates (MOR) were calculated by the following equation:

$$
\mathrm{MOR}={ }^{14} \mathrm{CO}_{2} \times \mathrm{CH}_{4} /\left({ }^{14} \mathrm{CH}_{4} \times \mathrm{v} \times \mathrm{t}\right)
$$

where ${ }^{14} \mathrm{CO}_{2}$ is the activity of the microbially-produced $\mathrm{CO}_{2}, \mathrm{CH}_{4}$ is the amount of $\mathrm{CH}_{4}$ in the sample, 
${ }^{14} \mathrm{CH}_{4}$ is the activity of the injected $\mathrm{CH}_{4}, \mathrm{v}$ is the volume of the sediment and $\mathrm{t}$ is the incubation time.

\section{DNA extraction}

For metagenomic analysis, cores I and II were pushed out from the liners and the $0-4 \mathrm{~cm}$ bsf and the 10-15 $\mathrm{cm}$ bsf horizons were removed for DNA extraction. Multiple parallel $0.5 \mathrm{~g}$ subsamples of the cores at each horizon were used for DNA extraction. Total genomic DNA was extracted with a FastDNA ${ }^{\circledR}$ SPIN for Soil Kit (MP Biomedicals) and cleaned using Wizard DNA Clean-Up (Promega) according to the manufacturer's instructions. The DNA quality was assessed by agarose gel electrophoresis and by optical density using a NanoDrop instrument (NanoDrop Products, Thermo Scientific). To get enough high quality DNA for the subsequent 454 sequencing DNA, subsamples from the same horizon were pooled. Of the total DNA isolated from the $0-4 \mathrm{~cm}$ horizon, $35 \%$ originated from core I and $65 \%$ from core II. For the 10-15 cm horizon, 38\% was isolated from core I and $62 \%$ from core II.

\section{4 sequencing}

For creation of the metagenomic libraries, $9.8 \mu \mathrm{g}$ DNA of the $0-4 \mathrm{~cm}$ sample and $6.8 \mu \mathrm{g}$ of the $10-15 \mathrm{~cm}$ sample were used. Sample preparation and sequencing of the extracted DNA were performed at the Norwegian High-Throughput Sequencing Centre (NSC) at CEES [55], University of Oslo according to standard GS FLX Titanium protocols, except that after the initial dsDNA immobilization, ssDNA was brought into solution by adding $50 \mu \mathrm{l} 1 \times \mathrm{TE}$ to the beads, followed by $2 \mathrm{~min}$ at $90^{\circ} \mathrm{C}$ and rapid cooling on ice.

The samples were tagged (fusion primers with tag sequences were used to mark sample origin), mixed and sequenced on a $70 \times 75$ format PicoTiterPlate ${ }^{\mathrm{TM}}$ on a GS FLX titanium instrument.

The metagenomic reads have been submitted to the Genbank Sequence Read archive [GeneBank: SRP005641].

The average of the mean quality score per sequence was 33.1 (standard deviation: 3.6) and 32.9 (standard deviation: 3.5) for the $0-4 \mathrm{~cm}$ metagenome and 10-15 $\mathrm{cm}$ metagenome respectively.

\section{Replicate removal}

Replicate reads were removed from the two metagenomes using the 454 Replicate filter [56,57]. Standard settings of a sequence identity cut off of 0.9 , a length difference requirement of 0 and a number of beginning base pairs to check of 3, were used. After removal of replicates, the $0-4 \mathrm{~cm}$ metagenome contained 525 reads with more than 2 ambiguous bases and 1222 reads with long homopolymers (>10 nt), making a total of 1733
(0.65\%) low quality reads. The $10-15 \mathrm{~cm}$ metagenome contained 395 reads with more than 2 ambiguous bases and 143 reads with long homopolymers (> $10 \mathrm{nt}$ ), making a total of $535(0.28 \%)$ low quality reads.

\section{Taxonomic classification}

The reads were taxonomically classified by BlastX query against the NCBI non-redundant Protein Database (ncbiP-nr) [58]. The computation was performed at the freely available Bioportal computer service [59]. Maximum expectation-value was set to 10.0 and maximum 25 alignments were reported per hit. The BlastX output files were analysed according to NCBI taxonomy in the program MEGAN, version 3.9 [44] with default LCAparameters (Min Score: 35, Top Percent: 10.0 and Min Support: 5). We used the option "enable all taxa" in MEGAN in order to account for reads with hits to the artificial taxa archaeal and bacterial "environmental samples".

\section{Rarefaction analysis}

The species richness was estimated by rarefaction analysis performed in MEGAN [44]. The MEGAN program uses an LCA-algorithm to bin reads to taxa based on their blast-hits. This results in a rooted tree where each node represents a taxon. The leaves in this tree are then used as OTUs in the rarefaction analysis. The program randomly chooses $10 \%, 20 \% \ldots 100 \%$ of the total number of reads as subsets. For each of these random subsets the number of leaves (hit with at least 5 reads (Min Support) is determined. This sub sampling is repeated 20 times and then the average value is used for each percentage. We did the analysis at the most resolved level of the NCBI taxonomy to capture as much of the richness as possible. At this level, the leaves are mostly strains and species but also some sequences like fosmids and plasmids are included. In cases were no reads are assigned to species the most detailed taxonomic level with 5 reads or more assigned are used.

The analysis was performed for total taxa in the metagenomes (including Bacteria, Archaea, Eukaryota, Viruses and Environmental sequences), and separately for archaeal and bacterial taxa.

\section{Comparison of metagenomes}

The metagenomes were compared at the phylum, class and genus level in MEGAN using absolute read counts [44]. Tabulated text files for each level were extracted from MEGAN and analyzed in the following manner: The metagenomes were normalized to the size of the smallest metagenome. Taxa without matches in one metagenome, or with less than 20 reads in both metagenomes, were removed from the comparison since they (due to their low abundance) could have been identified 
by chance and thereby represent uninformative data. The resulting normalized comparison was analyzed for overrepresented taxa using XIPE-totec with 20.000 samplings and with a confidence cut-off of $0.95,0.98$ and $0.99[25]$.

\section{Metabolic potential}

Reads were annotated to KEGG Orthologe (KO)-identifiers using KEGG Automatic Annotation Server (KAAS) $[60,61]$. Parameters used were: single-directional best hit, default bit score (60) and 40 manually selected reference genomes (Additional file 5, Table S5). Reference genomes were chosen from the most abundant species present in the metagenomes based on annotation in MEGAN.

The KO-identifiers were, if possible, replaced by corresponding Enzyme Commission (EC)-numbers using the Kyoto Encyclopedia of Genes and Genomes (KEGG) Orthology database [62-65].

Lists of unique EC and $\mathrm{KO}$ numbers (when no ECnumber was obtained) were created for each metagenome. These lists were then used to plot metabolic pathways for the two metagenomes onto metabolic pathway maps using KEGG Mapper: Colour Objects in KEGG Pathways [62-65].

\section{Signature genes for methane oxidation}

The reads were compared to protein sequence libraries for methyl-coenzyme $\mathrm{M}$ reductase $(m c r \mathrm{~A})$, particulate methane monooxygenase (pmoA) and dissimilatory sulphite reductase $(d s r \mathrm{AB})$ on the freely available Bioportal computer service [59]. The reference library for each enzyme was downloaded from Fungene (Functional gene pipeline \& repository) version v6.1 [66]. We limited the libraries by selecting only the sequences with a score (bits saved) of 100 or more from the HMMER Hidden Markov Model search against NCBIs nonredundant protein database. We used blastX against the protein sequences of each enzyme library with a maximum expectation value of 1.0E-20 [58]. Maximum one alignment was reported.

BlastX output files were further analyzed using NCBItaxonomy in MEGAN, version 3.9 [44]. The LCA-parameters were set to: Min Score: 35, Top Percent: 10.0 and Min Support: 1. All taxa were enabled.

\section{Estimates of effective genome sizes (EGS) and sampling probabilities of individual genes}

EGS was calculated according to the method developed by Raes et al [48] using the parameters a $=18.26, \mathrm{~b}=$ 3650 and $c=0.733$. Blast against a subset of the STRING database (v9.0), containing the COGs concerned, were conducted at the freely available Bioportal computer service $[59,67]$.
Sampling probability of the individual marker genes and expected number of sequences detected was calculated according to Beszteri et al [68]. We calculated with an average copy number of two for pmoA [69] and one for mcrA and dsr AB [70-72]. Average marker gene length was based on the reads present in the respective marker gene databases.

\section{Additional material}

Additional file 1: Table S1. Calculations based on estimated Effective Genome Sizes. (References are listed in the reference list of the main manuscript).

Additional file 2: Table S2. Reads assigned to bacterial taxa at the genus level in MEGAN (more than $0.1 \%$ of total reads assigned in at least one of the samples). All percentages are given as the percentage of total reads for each filtered metagenome.

Additional file 3: Table S3. Reads assigned to archaeal taxa at the genus level in MEGAN (more than $0.1 \%$ of total reads assigned in at least one of the samples). All percentages are given as the percentage of total reads for each filtered metagenome.

Additional file 4: Table S4. Reads length distribution for reads assigned at different taxonomic levels in MEGAN.

Additional file 5: Table S5. Genomes used for KAAS annotation.

\section{Acknowledgements}

The project was granted by VISTA/Statoil. OEH and the analytical costs were financed by project 6151 to AGR and THAH was financed by project 6503 to KSJ. The project was also supported by Norwegian Geotechnical Institutes education fund. We thank UC Santa Barbara Marine Operation divers in cooperation with David Valentine and Frank Kinnaman at UCSB for the core samples. We acknowledge David Valentine for valuable comments on the manuscript. The methane oxidation rate data of the cores and the seep gas analysis were generated by Frank Kinnaman and Blair Paul (UCSB) and kindly provided to our metagenomic project.

\section{Author details}

${ }^{1}$ Norwegian Geotechnical Institute, Sognsveien 72, P.O. Box 3930 Ullevål Stadion, N-0806 Oslo, Norway. ${ }^{2}$ Department of Molecular Biosciences, University of Oslo, Blindernveien 31, P.O. Box 1041 Blindern, N-0316 Oslo, Norway. ${ }^{3}$ Microbial Evolution Research Group, MERG, Department of Biology, University of Oslo, Blindernveien 31, P.O. Box 1066 Blindern, N-0316 Oslo, Norway. ${ }^{4}$ Centre for Evolutionary and Ecological Synthesis (CEES), Department of Biology, University of Oslo, Blindernveien 31, P.O. Box 1066 Blindern, N-0316 Oslo, Norway.

\section{Authors' contributions}

OEH participated in the design of the study carried out the taxonomic marker gene and pathway analyses and drafted the manuscript. THAH participated in the design of the study and performed the statistical analysis. TK and KSJ participated in the design of the study. AGR conceived the study, participated in its design and isolated DNA from the sediment samples acquired during her stay in David Valentines group at the University of California Santa Barbara. All authors helped revise the manuscript. All authors read and approved the final manuscript.

Received: 8 June 2011 Accepted: 4 October 2011

Published: 4 October 2011

\section{References}

1. Hornafius JS, Quigley D, Luyendyk BP: The world's most spectacular marine hydrocarbon seeps (Coal Oil Point, Santa Barbara Channel, California): Quantification of emissions. J Geophys Res 1999, 104(C9):20703-20711. 
2. Boles JR, Eichhubl P, Garven G, Chen J: Evolution of a hydrocarbon migration pathway along basin-bounding faults: Evidence from fault cement. Am Assoc Pet Geol Bull 2004, 88(7):947-970.

3. Luyendyk B, Kennett J, Clark JF: Hypothesis for increased atmospheric methane input from hydrocarbon seeps on exposed continental shelves during glacial low sea level. Marine and Petroleum Geology 2005, 22(4):591-596

4. Reeburgh WS: Oceanic methane biogeochemistry. Chem Rev 2007, 107(2):486-513.

5. Reeburgh WS: "Soft spots" in the global methane budget. Microbial Growth on C1 Compounds 1996, 334-342.

6. Niemann H, Lösekann T, de Beer D, Elvert M, Nadalig T, Knittel K, Amann R, Sauter EJ, Schlüter M, Klages M, et al: Novel microbial communities of the Haakon Mosby mud volcano and their role as a methane sink. Nature 2006, 443(7113):854-858

7. Knittel K, Lösekann T, Boetius A, Kort R, Amann R: Diversity and distribution of methanotrophic archaea at cold seeps. Appl Environ Microbiol 2005, 71(1):467-479

8. Hinrichs KU, Hayes JM, Sylva SP, Brewer PG, DeLong EF: Methaneconsuming archaebacteria in marine sediments. Nature 1999 398(6730):802-805

9. Orphan VJ, Hinrichs KU, Ussler W, Paull CK, Taylor LT, Sylva SP, Hayes JM, Delong EF: Comparative analysis of methane-oxidizing archaea and sulfate-reducing bacteria in anoxic marine sediments. Appl Environ Microbiol 2001, 67(4):1922-1934.

10. Boetius A, Ravenschlag K, Schubert CJ, Rickert D, Widdel F, Gieseke A, Amann R, Jørgensen BB, Witte U, Pfannkuche O: A marine microbial consortium apparently mediating anaerobic oxidation of methane. Nature 2000, 407(6804):623-626

11. Hallam SJ, Putnam N, Preston CM, Detter JC, Rokhsar D, Richardson PM, DeLong EF: Reverse methanogenesis: Testing the hypothesis with environmental genomics. Science 2004, 305(5689):1457-1462.

12. Meyerdierks A, Kube M, Kostadinov I, Teeling H, Glöckner FO, Reinhardt R, Amann R: Metagenome and mRNA expression analyses of anaerobic methanotrophic archaea of the ANME-1 group. Environ Microbiol 2010, 12(2):422-439.

13. Knittel K, Boetius A: Anaerobic oxidation of methane: Progress with an unknown process. Annu Rev Microbiol 2009, 63:311-334.

14. Dunfield PF, Yuryev A, Senin P, Smirnova AV, Stott MB, Hou SB, Ly B, Saw $J H$, Zhou ZM, Ren $Y$, et al: Methane oxidation by an extremely acidophilic bacterium of the phylum Verrucomicrobia. Nature 2007, 450(7171):879-882

15. Islam T, Jensen $S$, Reigstad $\amalg$, Larsen $\varnothing$, Birkeland NK: Methane oxidation at $55^{\circ} \mathrm{C}$ and $\mathrm{pH} 2$ by a thermoacidophilic bacterium belonging to the Verrucomicrobia phylum. Proc Natl Acad Sci USA 2008, 105(1):300-304.

16. Pol A, Heijmans K, Harhangi HR, Tedesco D, Jetten MSM, Op den Camp HJM: Methanotrophy below $\mathrm{pH} 1$ by a new Verrucomicrobia species. Nature 2007, 450:874-878.

17. Dumont MG, Murrell JC: Community-level analysis: Key genes of aerobic methane oxidation. Environ Microbiol 2005, 397:413-427.

18. Stoecker K, Bendinger B, Schöning B, Nielsen PH, Nielsen JL, Baranyi C Toenshoff ER, Daims H, Wagner M: Cohn's Crenothrix is a filamentous methane oxidizer with an unusual methane monooxygenase. Proc Nat Acad Sci USA 2006, 103(7):2363-2367.

19. Conrad R: The global methane cycle: recent advances in understanding the microbial processes involved. Environ Microbiol Rep 2009, 1(5):285-292.

20. Hanson RS, Hanson TE: Methanotrophic bacteria. Microbiol Rev 1996, 60(2):439-471.

21. Ding $\mathrm{H}$, Valentine $\mathrm{DL}$ : Methanotrophic bacteria occupy benthic microbial mats in shallow marine hydrocarbon seeps, Coal Oil Point, California. $J$ Geophys Res 2008, 113(G1)

22. Redmond MC, Valentine DL, Sessions AL: Identification of novel methane-, ethane-, and propane-oxidizing bacteria at marine hydrocarbon seeps by stable isotope probing. Appl Environ Microbiol 2010, 76(19):6412-6422.

23. Kinnaman FS, Kimball JB, Busso L, Birgel D, Ding HB, Hinrichs KU, Valentine DL: Gas flux and carbonate occurrence at a shallow seep of thermogenic natural gas. Geo-Mar Lett 2010, 30(3-4):355-365.

24. Treude T, Ziebis W: Methane oxidation in permeable sediments at hydrocarbon seeps in the Santa Barbara Channel, California. Biogeosciences 2010, 7(10):3095-3108.
25. Rodriguez-Brito B, Rohwer F, Edwards RA: An application of statistics to comparative metagenomics. BMC Bioinformatics 2006, 7.

26. Yamamoto M, Nakagawa S, Shimamura S, Takai K, Horikoshi K: Molecular characterization of inorganic sulfur-compound metabolism in the deepsea epsilonproteobacterium Sulfurovum sp NBC37-1. Environ Microbiol 2010, 12(5):1144-1152.

27. Hallam SJ, Girguis PR, Preston CM, Richardson PM, DeLong EF Identification of methyl coenzyme $M$ reductase $\mathrm{A}(\mathrm{mcr})$ genes associated with methane-oxidizing archaea. Appl Environ Microbiol 2003, 69(9):5483-5491

28. Meyerdierks A, Kube M, Lombardot T, Knittel K, Bauer M, Glöckner FO, Reinhardt R, Amann R: Insights into the genomes of archaea mediating the anaerobic oxidation of methane. Environ Microbiol 2005, 7(12):1937-1951.

29. Miyazaki J, Higa R, Toki T, Ashi J, Tsunogai U, Nunoura T, Imachi H, Takai K Molecular characterization of potential nitrogen fixation by anaerobic methane-oxidizing archaea in the methane seep sediments at the number 8 Kumano Knoll in the Kumano Basin, offshore of Japan. Appl Environ Microbiol 2009, 75(22):7153-7162.

30. Ettwig KF, Shima S, van de Pas-Schoonen KT, Kahnt J, Medema MH, op den Camp HJM, Jetten MSM, Strous M: Denitrifying bacteria anaerobically oxidize methane in the absence of Archaea. Environ Microbiol 2008, 10(11):3164-3173.

31. Ettwig KF, van Alen T, van de Pas-Schoonen KT, Jetten MSM, Strous M: Enrichment and molecular detection of denitrifying methanotrophic bacteria of the NC10 phylum. Appl Environ Microbiol 2009, 75(11):3656-3662.

32. Ettwig KF, Butler MK, Le Paslier D, Pelletier E, Mangenot S, Kuypers MMM, Schreiber F, Dutilh BE, Zedelius J, de Beer D, et al: Nitrite-driven anaerobic methane oxidation by oxygenic bacteria. Nature 2010, 464(7288):543-548.

33. Bahr M, Crump BC, Klepac-Ceraj V, Teske A, Sogin ML, Hobbie JE: Molecular characterization of sulfate-reducing bacteria in a New England salt marsh. Environ Microbiol 2005, 7(8):1175-1185.

34. Giloteaux L, Goñi-Urriza M, Duran R: Nested PCR and New Primers for analysis of sulfate-reducing bacteria in low-cell-biomass environments. Appl Environ Microbiol 2010, 76(9):2856-2865.

35. Kaneko R, Hayashi T, Tanahashi M, Naganuma T: Phylogenetic diversity and distribution of dissimilatory sulfite reductase genes from deep-sea sediment cores. Mar Biotechnol 2007, 9(4):429-436.

36. Madrid VM, Aller RC, Aller JY, Chistoserdov AY: Evidence of the activity of dissimilatory sulfate-reducing prokaryotes in nonsulfidogenic tropical mobile muds. FEMS Microbiol Ecol 2006, 57(2):169-181.

37. Nakagawa T, Nakagawa S, Inagaki F, Takai K, Horikoshi K: Phylogenetic diversity of sulfate-reducing prokaryotes in active deep-sea hydrothermal vent chimney structures. FEMS Microbiol Lett 2004, 232(2):145-152.

38. Smith AC, Kostka JE, Devereux R, Yates DF: Seasonal composition and activity of sulfate-reducing prokaryotic communities in seagrass bed sediments. Aquat Microb Ecol 2004, 37(2):183-195.

39. Lloyd KG, Lapham L, Teske A: An anaerobic methane-oxidizing community of ANME- $1 \mathrm{~b}$ archaea in hypersaline Gulf of Mexico sediments. Appl Environ Microbiol 2006, 72(11):7218-7230

40. Jiang $\sqcup$, Zheng YP, Peng XT, Zhou HY, Zhang $C L$, Xiao X, Wang FP: Vertical distribution and diversity of sulfate-reducing prokaryotes in the Pearl River estuarine sediments, Southern China. FEMS Microbiol Ecol 2009, 70(2):249-262.

41. Mussmann M, Richter M, Lombardot T, Meyerdierks A, Kuever J, Kube M, Glöckner FO, Amann R: Clustered genes related to sulfate respiration in uncultured prokaryotes support the theory of their concomitant horizontal transfer. J Bacteriol 2005, 187(20):7126-7137.

42. Schmalenberger A, Drake HL, Küsel K: High unique diversity of sulfatereducing prokaryotes characterized in a depth gradient in an acidic fen. Environ Microbiol 2007, 9(5):1317-1328.

43. Hugenholtz P: Exploring prokaryotic diversity in the genomic era. Genome Biology 2002, 3(2)

44. Huson DH, Auch AF, Qi J, Schuster SC: MEGAN analysis of metagenomic data. Genome Res 2007, 17(3):377-386.

45. Kunin V, Copeland A, Lapidus A, Mavromatis K, Hugenholtz P: A Bioinformatician's Guide to Metagenomics. Microbiol Mol Biol Rev 2008, 72(4):557-578. 
46. Mitra S, Schubach M, Huson DH: Short clones or long clones? A simulation study on the use of paired reads in metagenomics. $B M C$ Bioinformatics 2010, 11.

47. Jain R, Rivera MC, Lake JA: Horizontal gene transfer among genomes: The complexity hypothesis. Nov 08-09 1998; Irvine, California Natl Acad Sciences;3801-3806.

48. Raes J, Korbel JO, Lercher MJ, von Mering C, Bork P: Prediction of effective genome size in metagenomic samples. Genome Biol 2007, 8(1):R10.

49. Quaiser A, Zivanovic Y, Moreira D, López-García P: Comparative metagenomics of bathypelagic plankton and bottom sediment from the Sea of Marmara. ISME J 2011, 5(2):285-304.

50. Valentine DL: Emerging topics in marine methane biogeochemistry. Ann Rev Mar Sci 2011, 3(1):147-171.

51. Nauhaus K, Treude T, Boetius A, Krüger M: Environmental regulation of the anaerobic oxidation of methane: a comparison of ANME-I and ANME-II communities. Environ Microbiol 2005, 7(1):98-106.

52. Merkel A, Chernykh N, Kanapatskii T, Pimenov N: Detection of methanotrophic archaea in pockmark sediments (Gdansk Deep, Baltic Sea) by sequence analysis of the gene encoding the a subunit of methyl-coenzyme M reductase. Microbiology 2010, 79(6):849-852

53. Pernthaler A, Dekas AE, Brown CT, Goffredi SK, Embaye T, Orphan VJ: Diverse syntrophic partnerships from deep-sea methane vents revealed by direct cell capture and metagenomics. Proc Natl Acad Sci USA 2008 105(19):7052-7057.

54. Duffy M, Kinnaman F, Valentine DL, Keller E, Clark JF: Gaseous emission rates from natural petroleum seeps in the Upper Ojai Valley, California. Environmental Geosciences 2007, 14(4):197-207.

55. Norwegian High-Throughput Sequencing Centre (NSC). [http://www. sequencing.uio.no/].

56. Gomez-Alvarez V, Teal TK, Schmidt TM: Systematic artifacts in metagenomes from complex microbial communities. ISME J 2009 3:1314-1317.

57. 454 Replicate Filter. [http://microbiomes.msu.edu/replicates/].

58. Altschul SF, Gish W, Miller W, Myers EW, Lipman DJ: Basic local alignment search tool. J Mol Biol 1990, 215(3):403-410.

59. Bioportal. [http://www.bioportal.uio.no]

60. Moriya Y, Itoh M, Okuda S, Yoshizawa AC, Kanehisa M: KAAS: an automatic genome annotation and pathway reconstruction server. Nucleic Acids Res 2007, 35:W182-W185.

61. KAAS - KEGG Automatic Annotation Server. [http://www.genome.ad.jp/ tools/kaas/].

62. Kanehisa M, Goto S: KEGG: Kyoto Encyclopedia of Genes and Genomes. Nucleic Acids Res 2000, 28(1):27-30.

63. Kanehisa M, Goto S, Furumichi M, Tanabe M, Hirakawa M: KEGG for representation and analysis of molecular networks involving diseases and drugs. Nucleic Acids Res 2010, 38:D355-D360.

64. Kanehisa M, Goto S, Hattori M, Aoki-Kinoshita KF, Itoh M, Kawashima S, Katayama T, Araki M, Hirakawa M: From genomics to chemical genomics: new developments in KEGG. Nucleic Acids Res 2006, 34:D354-D357.

65. KEGG: Kyoto Encyclopedia of Genes and Genomes. [http://www.genome. $\mathrm{jp} / \mathrm{kegg} /$.

66. Functional gene pipeline \& repository. [http://fungene.cme.msu.edu/index spr].

67. STRING - Known and Predicted Protein-Protein Interactions. [http://stringdb.org/newstring_cgi/show_input_page.pl? Userld=Frnr4khlceg0\&sessionld=t73cGl|GN8OV]

68. Beszteri B, Temperton B, Frickenhaus S, Giovannoni SJ: Average genome size: a potential source of bias in comparative metagenomics. ISME J 2010, 4(8):1075-1077.

69. Murrell JC, Gilbert B, McDonald IR: Molecular biology and regulation of methane monooxygenase. Arch Microbiol 2000, 173(5-6):325-332.

70. Klein M, Friedrich M, Roger AJ, Hugenholtz P, Fishbain S, Abicht $H$, Blackall LL, Stahl DA, Wagner M: Multiple lateral transfers of dissimilatory sulfite reductase genes between major lineages of sulfate-reducing prokaryotes. J Bacteriol 2001, 183(20):6028-6035.

71. Thauer RK: Biochemistry of methanogenesis: a tribute to Marjory Stephenson. Microbiology-Uk 1998, 144:2377-2406.

72. Juottonen $\mathrm{H}$ : Archaea, Bacteria, and methane production along environmental gradients in fens and bogs. PhD thesis University of Helsinki; 2008. doi:10.1186/1471-2180-11-221

Cite this article as: Håvelsrud et al:: A metagenomic study of methanotrophic microorganisms in Coal Oil Point seep sediments. BMC Microbiology 2011 11:221.

\section{Submit your next manuscript to BioMed Central and take full advantage of:}

- Convenient online submission

- Thorough peer review

- No space constraints or color figure charges

- Immediate publication on acceptance

- Inclusion in PubMed, CAS, Scopus and Google Scholar

- Research which is freely available for redistribution

Submit your manuscript at www.biomedcentral.com/submit
C Biomed Central 